\title{
FORMAÇÃO DOCENTE NOS ESPAÇOS SOCIODIALÓGICOS FRONTEIRIÇOS: CONTRIBUIÇÕES DA ANÁLISE DIALÓGICA DO DISCURSO
}

\section{TEACHER EDUCATION IN SOCIO-DIALOGICAL FRONTIER REGIONS: CONTRIBUTIONS OF DIALOGIC DISCOURSE ANALYSIS}

\section{Maria do Socorro de Almeida Farias-Marques* Isaphi Marlene Jardim Alvarez}

\section{RESUMO}

Viver na fronteira é viver em um entremeio discursivo, cultural e identitário, caracterizado pelas especificidades que marcam tal lugar. Uma das particularidades desse espaço é a presença tanto da língua portuguesa quanto da língua espanhola como algo que é constitutivo das interações cotidianas fronteiriças. Esse encontro de línguas é desde o final dos anos 50 foco de diversos estudos que se centram tanto na nomenclatura dada ao encontro linguístico singular da fronteira como nas discussões acerca da formação de professores em região de fronteira, por exemplo. Diante disso, este trabalho busca promover uma reflexão inicial, com base na análise dialógica do discurso, que integre esses dois eixos de discussão.

Palavras-chave: fronteiras, formação docente, análise dialógica.

\section{ABSTRACT}

Living on the frontier is to live in a discursive, cultural and identity insertion, characterized by specific features that make part of this place. One of the peculiarities is the presence of the Portuguese language and the Spanish language as something that constitutes the frontier everyday interactions. This meeting of languages, since the 50s, is the focus of several studies that research not only the nomenclature given to this particular linguistic meeting, but also the discussions about teacher education in the frontier region. Thus, this paper seeks to offer initial thoughts about these two lines of discussion based on dialogic discourse analysis.

Keywords: frontiers, teacher education, dialogical analysis

\footnotetext{
* Universidade Federal do Pampa (UNIPAMPA), Bagé (RS). Brasil. fariasmarquessocorro@gmail. $\mathrm{com}_{i}$ Universidade Federal do Pampa (UNIPAMPA), Bagé (RS).Brasil. isaphi.jalvarez@gmail.com
} 


\section{INTRODUÇÃO}

A dinâmica da fronteira Brasil-Uruguai, os movimentos na fronteira, o ir e vir, esse entre-lugar particular de línguas/culturas mescladas em contato, que constituem o sujeito fronteiriço, impele-nos a estar constantemente refletindo sobre esse espaço de misturas. Viver na fronteira é viver em um entremeio discursivo, cultural e identitário, caracterizado por especificidades às vezes insuspeitadas que marcam tal lugar. Uma das particularidades desse espaço é a presença tanto da língua portuguesa quanto da língua espanhola como algo que é constitutivo das interações cotidianas fronteiriças.

Esse encontro de línguas é, desde o final dos anos 50, foco de diversos estudos que se centram tanto na nomenclatura dada ao encontro linguístico singular da fronteira quanto nas discussões acerca da formação de professores em região de fronteira, por exemplo. Diante disso, este trabalho busca promover uma reflexão inicial que integre esses dois eixos de discussão.

Para tanto, vamos fazer um panorama dos trabalhos já realizados sobre: (1) os encontros cotidianos das línguas e como as designações dadas a esses encontros vão se (re)construindo e se (re)significando nos espaços sóciodialogicos fronteiriços; e (2) de que forma a singularidade linguística da fronteira pode ser contemplada nos Cursos de Letras da Unipampa ( Câmpus Bagé e Câmpus Jaguarão), visando a formação docente em região de fronteira.

A priori, situaremos, brevemente, a Universidade à qual estamos vinculadas, pois um dos seus objetivos é fomentar tanto a integração quanto o desenvolvimento nas regiões de fronteira. A Instituição é formada por dez Campi. Desses, há dois que estão localizados na fronteira entre Brasil e Argentina - os Campi de Uruguaiana e São Borja; e três estão em cidades brasileiras que são fronteira com o Uruguai, são eles: Campi de Bagé, Jaguarão e Sant'ana do Livramento.

A Universidade Federal do Pampa (Unipampa) é fruto de um projeto de expansão das Instituições Federais de Educação Superior promovido pelo Governo Federal a partir de mobilizações de dirigentes de alguns municípios da metade sul do Rio Grande do Sul. A instalação e a criação da Universidade foram e ainda são marcadas pela responsabilidade de contribuir para o desenvolvimento socioeconômico e educacional da região, conhecida como a metade sul do Rio Grande do Sul.

De acordo com Projeto de Desenvolvimento Institucional (PDI), a Missão da Unipampa é assumir "a missão de promover a educação superior de qualidade, com vistas à formação de sujeitos comprometidos e capacitados a atuarem em prol 
do desenvolvimento regional, nacional e internacional" (PDI, 2014, p.13) a partir da integração entre ensino, pesquisa e extensão.

Em consonância com o que foi exposto até o momento, o interesse em propor o presente estudo advém de leituras, discussões e reflexões realizadas durante o nosso período de doutoramento e em nossos projetos de pesquisa, as quais nos possibilitaram ampliar o modo de perceber o contexto de fronteira ${ }^{1}$, as questões linguísticas que se colocam sobre e nesse espaço e como elas respingam na formação de docentes, área de nosso interesse. Questões essas que dialogam com a nossa área de atuação e com o objetivo e a missão da Instituição.

Este trabalho está dividido em quatro seções. A primeira define e contextualiza a fronteira geopolítica; a segunda se caracteriza por traçar um breve panorama de trabalhos existentes sobre contato de línguas na fronteira e por fazer alusão à formação docente em região de fronteira; a terceira traz uma reflexão inicial, com base na análise dialógica do discurso, que integra esses dois eixos de discussão sobre análise de gêneros discursivos que circulam na fronteira. Por último, as considerações finais buscam sintetizar as nossas reflexões iniciais sobre este trabalho.

\section{PENSANDO A FRONTEIRA}

Tomamos a definição de fronteira como lugar geográfico para iniciar a reflexão sobre o que entendemos neste trabalho por fronteira geopolítica. O dicionário Aurélio Buarque de Holanda (1998, p. 381) traz a seguinte acepção: "Fronteira: substantivo feminino. 1. Extremidade dum país ou região do lado onde confina com outro; limite, raia. 2. Região adjacente a essa extremidade".

Nesta perspectiva, fronteira nos é definida como o limite, a raia, uma região de extremo o que nos leva a um entendimento geográfico de fronteira como um lugar de divisão, de separação ou o lugar que determina o fim do nosso território. De certo modo, o nosso fim e o início do outro. Esse conceito assim compreendido já nos remete a um embate entre o quanto a fronteira é real e o quanto ela é simbólica (imaginária).

Para Pesavento (2002, p. 36), "a fronteira é enfim, menos uma linha que um espaço, menos um marco físico ou natural que um sistema simbólico encerra em si um significado que opera para além dos aspectos territoriais". A partir de tais acepções, podemos observar que a fronteira significa em uma relação binária de oposição,

\footnotetext{
1 A fronteira a que nos referimos é a região entre o norte do Uruguai e sul do Rio Grande do Sul. Neste trabalho tomamos as fronteiras entre Brasil/Uruguai de Rio Branco/Jaguarão e Quarai/Artigas.
} 
representando aquilo que separa, marcando a distinção entre dois ou mais territórios, sinalizando a existência da diferença ao mesmo tempo em que os aproxima, através de uma ponte, de uma avenida, de marcos divisórios, entre outros. ${ }^{2}$

Quando trabalhamos com a noção de fronteira, devemos ter presente tanto a sua importância físico-geográfica, como a importância histórico-simbólica, pois dessa forma podemos evocar o que a fronteira inclui e o que está dela excluído. Ao delimitar fronteira numa perspectiva geográfica, apresentamos inicialmente uma definição do que, a partir da década de 80 , final da década de 70 , definiu-se como faixa de fronteira.

Machado da Silveira, Freitas e Adamczuk (2002, p. 14) mencionam que:

A faixa de fronteira está definida pela Lei n ${ }^{\circ} 6634$, de 02.05.79, a qual revogou a Lei $n^{\circ} 2597$, de 12.09.55, e também alterou o Decreto-lei ${ }^{\circ} 1135$, de 03.12.70. Foi durante o governo do Pres. Ernesto Geisel que se regulamentou os $150 \mathrm{Km}$ internos e paralelos à linha divisória terrestre do território brasileiro. Considerados "área indispensável à segurança nacional", tais territórios permanecem tendo restrições à implementação de atividades em seu espaço, pois neles está vedada, sem prévio assentimento do órgão federal competente, a prática de diferentes atos. Entre eles, a concessão de terras, a abertura de vias de transportes, a instalação de meios de comunicação, a construção de pontes, estradas internacionais e campos de pouso e outras atividades.

Conforme o estabelecido pela lei acima referida, a faixa de fronteira do Brasil meridional, a partir da confluência de diversos fatores, está composta por territórios geograficamente pertencentes à região da Campanha (ou fronteira sudoeste do Rio Grande do Sul), além das regiões das Missões e da Depressão Central, entre outros. Ou seja, não podemos ignorar que todos esses elementos mencionados, quando associados, geram uma fronteira sui generis que, mesmo confinando politicamente permanece contígua do ponto de vista cultural. Essa cultura permite estabelecer uma ligação que extrapola os limites físicos do estado-nação, transformando a presença da estrutura do estado na sua relação com os vizinhos do Uruguai e da Argentina.

A fronteira é um espaço que limita e separa, apontando direções aos sentidos. Percebemos que, mesmo nessa dimensão de abordagem fixada pela territorialidade e pela geopolítica, o conceito de fronteira avança para os domínios daquela construção simbólica de pertencimento a que chamamos identidade e que corresponde a um marco de referência imaginária definido pela diferença, conforme expõe Leenhardt (2002).

2 Sinalizamos que essas fronteiras são demarcadas geograficamente por pontes entre ambos os países e há um alto índice de circulação entre Brasil/Uruguai sem a obrigatoriedade aduaneira de praxe que se estabelece entre países limítrofes. 
Geograficamente se estabelece a diferença entre fronteiras naturais e artificiais:

\begin{abstract}
As fronteiras naturais são uma metáfora, porque a escolha de um marco é sempre uma escolha política, ainda que o marco físico continue sendo um rio ou uma montanha. Mas por que "esse" rio foi escolhido e não "aquele" outro logo ali à frente? Portanto, é sempre uma construção que acaba sendo social. Essa discussão é muito mais metafórica do que de fato uma discussão mais profunda em relação à essência da fronteira. Em nossa forma de entender as fronteiras não seriam nem naturais, nem artificiais, as fronteiras são marcos híbridos formados por materialidades (naturais e artificiais) e normas. Aquilo que Ratzel considera como fronteira demarcada é para ele uma fronteira artificial, não tendo qualquer marco físico, por isso seria necessária a construção de um marco artificial para a demarcação "no terreno" da delimitação prevista pelo Tratado estipulado entre os Estados ( CATAIA, 2008, p. 18).
\end{abstract}

As regiões e cidades de fronteiras, delimitadas ou não por obstáculos geográficos, são marcadas por uma formação linguística, identitária, cultural diferenciada. Segundo Schelle (2013), há na fronteira Brasil/Uruguai sujeitos que convivem com duas maneiras de falar: a dos dialetos fronteiriços do português do Brasil e a dos dialetos fronteiriços do espanhol do Uruguai, portanto sujeitos que convivem com práticas culturais de um ou do outro país, que se materializam na linguagem. Para o escritor (2004, p. 49), o território fronteiriço é um "plano de interseção de duas nacionalidades e de entrelaçamento de duas línguas, divididas pelas mais variadas delimitações de ordem oficial e até linguísticas". Então, afirma que estar na fronteira é se sentir como se "lá nós não somos nós, mas nosotros, nós outros nós-nos-outros" (SCHLEE, 2004, p. 49) e os outros em nós: vive-se a alteridade fronteiriça.

Nesse contexto, a proposta que temos de apontar para uma reflexão sobre a formação de docentes nos espaços sociodialógicos fronteiriços justifica-se pela necessidade que há de se discutir e agregar na formação do aluno de Letras conhecimentos sobre estudos que tratam não só a situação linguística, mas também social, identitária e histórica da referida região fronteiriça. Para dar seguimento à reflexão que trazemos, a seguinte seção se caracteriza por um panorama das pesquisas já realizadas acerca das designações dadas ao encontro, ao contato da língua portuguesa e da espanhola no espaço ao qual nos referimos.

\title{
2. "MISTURAS" FRONTEIRIÇAS
}

A partir de 1950 iniciou-se uma larga e consistente tradição de estudos sobre a fronteira Brasil/Uruguay na Universidad de la República (UDELAR)/Uruguai. 
Esses estudos evidenciaram de forma científica o encontro, contato entre as duas línguas da região. Trabalhos como os de Fustes (2010), Behares (2013) nos mostram que as variedades, ocasionadas pelos contatos linguísticos cotidianos, têm recebido diversas denominações ao longo dos anos tais como: portuñol, fronterizo, bayano, brasileiro, Dialeto Português Uruguaio (doravante DPU) e Português Uruguaio (doravante PU).

Nesse contexto, neste aparado, tais designações serão revisitadas, pois revelam não só o momento histórico das pesquisas e o enfoque de estudos adotado nas análises linguísticas, mas também desvelam a identidade construída dos sujeitos. Sujeitos da fronteira que se encontram no centro de um espaço o qual liga o norte e o noroeste do Uruguay com o Sul do Rio Grande do Sul e ao mesmo tempo separa dois países pela linha imaginária.

De acordo com Fustes (2010, p.69), as primeiras pesquisas acerca do encontro da língua espanhola com a língua portuguesa na fronteira uruguaia com Brasil começaram com Rona, no final da década de 50. Quando Rona iniciou seus estudos nessa zona fronteiriça afirmou que:

Cuando examinamos la zona de encuentro de estas dos lenguas, observamos, a pesar de lo dicho, la ausencia total de una reta línea divisoria y, lo que es más interesante todavía la formación de un dialecto intermedio por mezcla de ambas lenguas. (1963, p, 4)

O estudioso designa o encontro das duas línguas como um "dialecto intermedio", caracterizado pela "mezcla" das duas línguas. Rona (1963) se refere a um dialeto "dialecto fronterizo mixto" com base aparentemente portuguesa. Nas palavras do estudioso, o dialeto misto denominado fronterizo é "una mezcla de portugués y español, pero no es ni portugués ni español y resulta con frecuencia ininteligible tanto para los brasileños como para los uruguayos. Este dialecto es de base portuguesa, hispanizada." (RONA, 1963, p.10) O descobrimento de Rona, instaura, como afirma Fustes ( 2010, p.71), um:

objeto de estudio a un dialecto que presenta testimonios de dos lenguas clásicamente reconocibles a los oídos del lingüista y que, tomado en ese sentido, presenta, como sistema, un alto grado de variabilidad de formas, oscilaciones que hacen recordar al lingüista constantemente a una u otra, punto que será objeto de discusión a lo largo de años.

Os trabalhos desenvolvidos pelo linguista se caracterizaram pelo "carácter de la exploración dialectológica de tinte estructuralista" ( FUSTES, 2010, p 69). Sendo assim, desenvolveu suas pesquisas com foco na descrição fonética-fonológica, 
morfologia verbal, léxico e sintaxe do dialeto a fim de "establecer la extensión de isoglosas brasileñas", portuguesismos, que ainda não se conheciam.

A partir dos estudos que realizou, Rona chegou à conclusão de que cada zona dialectal está sempre determinada por isoglosas (portuguesas, castellanas). Nesse sentido, o estudioso $(1965$, p. 12) aponta a existência de três tipos de "mezcla", a saber: (1) os dois sistemas de isoglosas existem em sujeitos diferentes; (2) os dois sistemas de isoglossas coexistem no mesmo sujeito, resultando no sujeito bilíngue; (3) os dois sistemas de isoglossas existem de maneira parcial e complementar, resultando no dialeto misto.

Os três tipos de mescla classificados por Rona são possibilidades que estão à disposição dos falantes entre as quais ele pode escolher no seu discurso. Além dos tipos de mescla, as isoglossas indicam quatro variedades de subdialetos uruguaios: (1) artiguense, (2) tacuaremboense, (3) melense, (4) yaguaronense. Rona, ao delimitar esses quatro tipos de subdialetos, ao mesmo tempo que delimita a situação linguística de cada região, aponta que os falantes fronteiriços também são identificados pelas variedades que circulam nas fronteiras em que residem, trabalham ou estudam, não havendo, portanto, na fronteira, uma identificação única.

Nos anos seguintes, a partir dos achados de Rona, Elizaincin (1987) objetivou ampliar e complementar os estudos já realizados na perspectiva do contato de línguas. De acordo com Fustes (2010, p. 72), essa nova perspectiva fornece "las claves para tratar la problemática de la cuestión sujeto-lengua." Elizaincín caracterizou as falas fronteiriças como "dialectos bilíngues", pois assim poderia destacar a origem biforme dos dialetos fronteiriços mistos. Nessa linha, o estudioso caracteriza a fronteira como uma sociedade bilíngue e diglóssica. O sujeito bilíngue e diglóssico pode escolher a língua que deseja falar de acordo com os interlocutores e com o contexto de interação e também pode optar por alternar mais de uma língua na interação.

A isso Milroy \& Muysken (1995) chamam de code-switching, a alternância de línguas que os sujeitos fazem em uma conversa, por exemplo. Gonçalves (2013, p. 36), com base nas pequisas desses estudiosos, alega que "code-switching não é uma mistura de idiomas ou um conhecimento deficiente da língua por parte dos bilíngues, não se trata de uma incapacidade linguística dos falantes", mas, sim, de "um recurso adicional dos bilíngues, para que possam expressar-se nas mais diversas situações".

Diz ainda, com base em Grosjean (1982), que os sujeitos bilíngues alternam os códigos para preencher uma necessidade linguística, para citar alguém, para especificar o envolvimento com o seu interlocutor, para marcar a identidade de 
um grupo, para excluir alguém da conversa, para mudar o papel do falante. Essa alternância pode dar-se tanto entre enunciados quanto no mesmo enunciado.

Elizaincín argumenta que nessa sociedade bilíngue e diglóssica convivem e se superpõem o espanhol estándar em contextos formais e familiares da classe média e alta; o português estándar por alguns membros da comunidade uruguaia e bastante presente nos meios de comunicação "gaúchos", constituindo um "reforzador" dos DPUs; e os dialectos portugueses del Uruguay (DPU), caracterizados como uma variedade "baixa", subestándar utilizada nas esferas familiares e em contextos informais pela classe baixa.

Assim, Elizaincin, Behares e Barrios (1987, p.14) renomeiam o dialeto misto fronteiriço cunhado por Rona para "dialectos portugueses del Uruguay" e os definem como "formas mixtas (o "dialectos bilíngues" V. Haugen 1973) de base portuguesa, las que, sin embargo, evidencian fuerte influencia del español". A nova designação pluralizou a de Rona por dois motivos. Em primeiro lugar, de acordo com os autores, a escolha do vocábulo "dialectos" e não "dialecto" deu-se por entenderem que a situação linguística da fronteira não é harmônica e muito menos equilibrada, pois ocorre ali uma "situación intrinsecamente variable" (1987, p. 13). Em segundo lugar, o uso de "portugueses" está relacionado com a base lusitana dos dialetos, anteriormente confirmada por Rona. As investigações desses professores, nos anos 80, foram desenvolvidas no âmbito da morfossintaxe dos DPUs com o objetivo de observar a variabilidade das formas estruturais da língua espanhola e da língua portuguesa.

Seguindo os estudos acerca do encontro das línguas, Sturza (2005, p. 49) coloca que Punaren (1999) "ao pesquisar a atitude linguística dos uruguaios de Rivera, em relação ao prestígio do dialeto que praticam, decide designar o que Elizaincín chama de DPU, de portunhol". Diferente dos estudos anteriores, essa designação partiu da fala dos moradores da fronteira, ou seja, do senso comum. Os sujeitos da fronteira Rivera-Livramento se conhecem como falantes de portunhol, porém o entendimento de um "mal falar" permanece, ilustra a estudiosa.

Uma nova designação dada aos DPUs foi cunhada por Carvalho (2003). Enquanto para Elizaincín, Behares \& Barrios (1987) a situação linguística da fronteira resulta do convívio de um dialeto do espanhol com um dialeto do português do Uruguai, para Carvalho (2003) os sujeitos de fronteira falam um dialeto do português brasileiro. Sendo assim, Sturza (2005, p. 49) coloca que para Carvalho,

a situação das práticas linguísticas nessa zona fronteiriça é na verdade a caracterização de que português é esse que se pratica e como ele se distribui, dado a que a mistura dos sistemas linguísticos do português e do espanhol não são aleatórias tal como afirma Elizaincín, Behares \& Barrios (1987), mas são condicionadas por fatores extralinguísticos. 
Diante disso, a estudiosa entende que não há um encontro de dialetos de base espanhola e portuguesa, mas somente a presença de variantes do português: português brasileiro falado na zona urbana e português uruguaio falado na zona rural. A partir dessa reflexão, chegou à designação que defende: o português uruguaio (PU).

Esse encontro de línguas também pode ser analisado na perspectiva translinguística. Moita Lopes (2013) argumenta que estamos vivendo um tempo em que há uma expressiva mobilidade de pessoas e fluxo de pessoas de diferentes lugares, com diferentes línguas, costumes e culturas. Zolin-Vesz (2014, p. 325) entende o translinguismo e/ou a translíngua como resposta "aos complexos e multilíngues processos que encartam as práticas linguísticas das pessoas no mundo contemporâneo, pautado por fronteiras fluídas entre as línguas".

Sendo assim, as línguas que estão em jogo (portuguesa e espanhola), na fronteira, estão longe de serem entendidas como línguas autônomas, como sistemas fechados, em que os sujeitos são apagados e suas marcas sócio-históricas e ideológicas são desconsideradas em prol da pureza das línguas que representam o Estado-Nação, respectivamente (MOITA LOPES, 2013).

Nessa linha, o estudioso (2013, p. 104) acrescenta que as línguas não devem ser consideradas,

como sistemas autônomos fechados que apagam as pessoas e os usos que elas fazem das línguas, mas como trama invisível de fluxos que só ganha vida quando as pessoas e suas subjetividades e histórias são consideradas nas práticas sociais múltiplas e situadas de construção de significado em que atuam.

Assim, entender a linguagem "como prática local por meio da qual as línguas são um produto de atividades profundamente sociais e culturais nas quais as pessoas se engajam" é a forma como podemos estudar e valorizar as vidas sociais da fronteira materializadas na linguagem (MOITA LOPES, 2013, p. 106).

Dialogando com o contexto binacional, são as práticas sociais fronteiriças que fazem com que o encontro entre as línguas ocorra, ocasionando novos sentidos, novas formas de enunciar, novas práticas linguísticas locais. Nas zonas de contato e de fronteira, "as línguas passam a ser entendidas como recursos comunicativos multissemióticos, distribuídos desigualmente na sociedade e que as pessoas vão aprendendo aqui e ali, dependendo de suas necessidades". (MOITA LOPES, 2013, p. 109).

Diante desse panorama linguístico, que mostra a realidade sociolinguística do Uruguai e caracteriza os discursos produzidos na fronteira, buscamos na 
próxima seção estabelecer um diálogo com o nosso fazer docente e a formação de professores em região de fronteira.

\section{FORMAÇÃO DOCENTE EM REGIÕES DE FRONTEIRA}

A Unipampa, como foi mencionado anteriormente, é uma Instituição multicampi, distribuída por dez cidades gaúchas de médio e pequeno porte, instalada ao longo da fronteira do Brasil com o Uruguai (Câmpus Bagé, Jaguarão e Santana do Livramento) e com a Argentina (Câmpus de Uruguaiana e São Borja). Com as suas atividades didáticas iniciadas em setembro de 2006, teve, como uma de suas principais justificativas para sua criação, diminuir a disparidade econômica da região e, nesse sentido, repensar o aspecto educacional, além de fomentar a integração e o desenvolvimento dessas regiões de fronteira.

Nesse cenário, docentes do Curso de Letras do Campus Bagé e de Jaguarão começaram a pensar o ensino de línguas nesse espaço, com uma demanda expressiva de questões em aberto para serem desenvolvidas, com vistas às problemáticas que surgem no que tange ao ensino/aprendizagem de línguas na fronteira.

Essas problemáticas aparecem porque a região de fronteira é caracterizada como bilíngue, e nela circulam tanto a língua espanhola quanto a língua portuguesa em maior ou menor frequência de acordo com o país e a situação comunicativa em que os sujeitos estão envolvidos. Como pudemos observar na seção anterior, na região de fronteira além da presença das duas línguas referidas, também circulam outras variedades linguísticas que precisam ser valorizadas, ser discutidas nos espaços de ensino. Por essa razão, justifica-se a necessidade de voltar o olhar para as práticas linguísticas fronteiriças, focando a realidade sociolinguística da fronteira.

Diante disso, ficam algumas perguntas:

- Como trabalhar essa diversidade linguística da região de fronteira nos Cursos de Letras?

- Como realizar a prática de ensino frente a tal diversidade?

- Há uma preocupação do aluno em formação em relação à singularidade linguística desse espaço fronteiriço?

- Que conhecimento e/ou compreensão/aceitação/vivência dessa realidade têm os nossos alunos dos cursos referidos? 
Nesse sentido, vale a inserção sobre a temática fronteiriça nos cursos de Letras da UNIPAMPA dada a região geográfica em que a Instituição está inserida. Entretanto, é preciso estabelecer uma premissa sobre a questão da formação de professores de Letras no espaço especificado. Há a necessidade de se conhecer a complexidade linguística fronteiriça e também há a pertinência em focar a questão durante a formação dos discentes do Curso de Letras se o que desejamos é uma formação mais ampla, mais consciente e voltada para a atuação desse professor na Educação Básica regional, a qual tem discentes que sofrem com problemas de exclusão, com a invisibilidade, conforme Irala, Mota e Alvarez (2013, pag. 69), e com o despreparo dos docentes que ensinam línguas nas escolas, frente a essa situação.

Fernandes e Sturza (2009, p. 214) definem "língua próxima" como sendo a que "funciona em um estado de interface com a outra, pertence a um conjunto de representações sócio-históricas e interculturais que as identificam como tal"; são "línguas condicionadas à presença uma da outra." Nesse contexto, a língua espanhola, como já mencionamos, deixa de ser uma língua estrangeira porque as línguas (brasileira e uruguaia) são constituídas historicamente umas pelas outras e constituem o que conhecemos como espaço de enunciação fronteiriço (STURZA, 2006; MOTA, 2010).

A complexidade regional deve ser contemplada curricularmente, de forma mais específica em regiões de fronteira, conforme explicitam Irala, Mota e Alvarez (2014, p. 77):

Especialmente em uma região fronteiriça como é o caso dessa em que atuamos, um currículo que contemple práticas voltadas para a interculturalidade é de extrema relevância, dado que os alunos integram uma sociedade complexa deste ponto de vista, pois está permeada por sujeitos de diferentes identificações nacionais e/ou linguísticas que, muitas vezes, compartilham determinados constituintes culturais.

É preciso que o estudante compreenda o contexto social em que está inserido e as imbricações decorrentes dessa inserção. Para tanto, precisa ser exposto a esse outro e à diversidade que o cerca, além de aceitá-la e reconhecê-la, conforme explicita Gonzalez (2011, p. 146).

Nessa perspectiva, os documentos de la Comisión de Políticas Lingüísticas en la Educación Pública do Uruguay, recomendam:

el trabajo en el aula con producciones orales y escritas en la variedad local que permita analizar las diferencias dialectales y generar un espíritu de respecto y valoración de las tradiciones culturales propias de la región (2008, p. 69). 
Entendemos que é preciso pensar como trabalhar a diversidade linguística a partir de um uso contextualizado da linguagem, considerando as práticas sociais reais, do cotidiano, da realidade fronteiriça. Essa metodologia de trabalho pode ser desenvolvida com o uso de material autêntico, a partir de amostras de gêneros discursivos que aí circulam.

A concepção de gêneros discursivos que adotamos é a da análise/teoria dialógica do discurso, desenvolvida por Bakhtin e pelo Círculo, a qual é marcada pela indissociável relação entre sujeitos, língua, linguagens e história. Além disso, pensar o ensino pelo viés dos gêneros possibilita ao professor ativar outros conceitos como de heteroglossia, hibridismo, cronotopo, por exemplo. A concepção de linguagem, na perspectiva dialógica, está apoiada nas relações discursivas empreendidas entre sujeitos historicamente situados. O discurso, portanto, é a língua em sua integridade concreta e viva.

A partir disso, Bakhtin (1992, p.183) afirma que as relações dialógicas são extralinguísticas e, portanto, não podem ser isoladas do discurso. Segundo o estudioso,

A linguagem só vive na comunicação dialógica que constitui o verdadeiro campo da vida da linguagem. Toda a vida da linguagem seja qual for seu campo de emprego (a linguagem cotidiana, a prática, a científica, a artística, etc.), está impregnada de relações dialógicas.

A concepção de linguagem defendida pelo Círculo e por Bakhtin é caracterizada como dialógica porque se entende que a língua/linguagem "têm seus sentidos produzidos pela presença constitutiva da intersubjetividade (interação entre subjetividades) no intercâmbio verbal, ou seja, nas situações concretas de exercício da linguagem" (SOBRAL, 2009, p. 32). Nessa direção, os gêneros do discurso para Bakhtin (1992, p. 268) são "as correias de transmissão entre a história da sociedade e a história da linguagem".

A proposta de trabalhar com amostras de gêneros que circulam na sociedade fronteiriça permite ampliar a competência linguística, discursiva dos alunos em formação e o reconhecimento das "misturas" nas mais diversas formas de participação social. Muitas vezes essas "misturas" são desvalorizadas, estigmatizadas, desprestigiadas e consideradas incorretas desqualificando os sujeitos da região. $\mathrm{Na}$ prática escolar e até mesmo superior ainda se promove e/ou se reforça o uso "correto" das línguas, ignorando a variedade linguística do aluno o que pode causar desde prejuízos académicos até afetivos e identitários.

Diante dessa situação, entendemos que é necessário iniciar pelos Cursos de Graduação em Letras uma sensibilização sociolinguística que se direcione para uma 
reflexão acerca da singularidade heteroglóssica fronteiriça, exposta neste trabalho. Isso contribuirá para que os docentes em formação estejam preparados para trabalhar com um público escolar característico de fronteira, que possui diferentes histórias linguísticas e que reside em um espaço linguisticamente híbrido como já foi cientificamente comprovado com os estudos anteriormente expostos, por exemplo.

Para a proposta que buscamos esboçar neste artigo, foram selecionadas cinco amostras de gêneros. A primeira foi retirada da corpórea de uma dissertação de Mestrado e reproduz uma conversa que ocorreu em uma loja comercial de Jaguarão entre uma vendedora e uma cliente. $\mathrm{O}$ segundo gênero é o poema 32 (treinta y dos), retirado da obra Noite nu norte do escritor uruguaio natural de Artigas (Uruguai), Fabián Severo. O terceiro é um anúncio de um restaurante, localizado na zona comercial de Río Branco (Uruguai), cidade fronteira com Jaguarão (Brasil) que foi fotografado por uma das autoras deste artigo em 2013. O quarto gênero é um folheto que divulga uma festa de final de ano que ocorreu no Balneário uruguaio Lago Merín em Rio Branco. O quinto também é um folheto cujo objetivo é divulgar uma festa binacional que ocorreu em um local destinado para baladas noturnas em Rio Branco (Uruguai).

A análise que se objetiva desenvolver com tais gêneros não busca ser exaustiva e tampouco deseja ser entendida como um modo diferente ou novo no tratamento com gêneros em sala de aula. A nossa discussão busca uma reflexão sobre os gêneros que mostram, a seu modo, o contato das línguas na fronteira entre Brasil e Uruguai. O nosso foco não recai na análise formal das "misturas" ou do comumente chamado portuñol, mas na tentativa de causar provocações e reflexões acerca da dimensão do que é trabalhar com línguas em tempos líquidos.

A proposta gira em torno de três palavras-chave: práticas de linguagem/ discursivas; situação específica de comunicação e gênero do discurso. Encontramos nas obras do Círculo um estudo que nos leva a uma análise metodológica sociodialógica. Em Marxismo e Filosofia da Linguagem encontramos a seguinte ordem de análise:

1.As formas e os tipos de interação verbal em ligação com as condições concretas em que se realiza.

2.As formas das distintas enunciações, dos atos de fala isolados, em ligação estreita com a interação de que constituem os elementos, isto é, as categorias de atos de fala na vida e na criação ideológica que se prestam a uma determinação pela interação verbal. 
3.A partir daí, exame das formas da língua na sua interpretação linguística habitual. (BAKHTIN (VOLOCHINOV), 1986, p.124)

A primeira fase contempla a situação comunicativa; a segunda, a descrição dos gêneros e, por último, o analista recorre à interpretação linguística. Em relação à análise de gêneros discursivos, Rojo (2005, p. 199) diz:

Aqueles que adotam a perspectiva dos gêneros do discurso partirão sempre de uma análise em detalhe dos aspectos sócio-históricos da situação enunciativa, privilegiando, sobretudo, a vontade enunciativa do locutor- isto é, sua finalidade, mas também e principalmente sua apreciação valorativa sobre seu(s) interlocutor (es) e tema(s) discursivos, e a partir desta análise, buscarão as marcas linguísticas (formas do texto/ enunciado e da língua- composição e estilo) que refletem, no enunciado/ exto, esses aspectos da situação.

A partir disso, o primeiro passo para a análise é atentar para a situação de comunicação - interlocutores envolvidos -, porque ela é a condição essencial para que se estabeleçam as relações sociais as quais "a partir do foco da apreciação valorativa do locutor (...) determinam muitos aspectos temáticos, composicionais e estilísticos do texto ou discurso" (ROJO, 2005, p. 197).

As relações sociais são organizadas de acordo com a distribuição dos lugares sociais, ou seja, ocorrem nas esferas de atuação humana, nas esferas comunicativas. Sobral (2009, p. 120) afirma que "o discurso apresenta um dado modo de ver o mundo, a sociedade, etc., que reflete a posição relativa dos que estão neles envolvidos- um dado locutor e um dado interlocutor típico". A posição relativa está vinculada diretamente com os gêneros ligados a uma ou a outra esfera de atividade humana, ou seja, os gêneros estão diretamente ligados a espaços sociais específicos. Por isso, "cada esfera de atividade humana tem sua própria forma de produção, de circulação e de recepção de discursos" (SOBRAL, 2009, p. 121).

Assim como a língua, os gêneros são afetados pela dinamicidade das condições de produção, circulação e recepção e definidos pelo endereçamento. Para Bakhtin, o direcionamento e as diferentes concepções de destinatários são particularidades que constituem e determinam os gêneros. O querer dizer, o modo de organizar e compor esse querer dizer é a base para a escolha do gênero o qual tem como índice constitutivo o dirigir-se a alguém. Segundo Bakhtin, (2000, p. 321) o destinatário é determinado pela esfera e pela "vida cotidiana a que se reporta um dado enunciado". Diante disso, quando se pensa em trabalhar com gêneros e analisá-los, as questões iniciais a serem contempladas são: "A quem se dirige o enunciado? Como o locutor (ou escritor) percebe e imagina seu destinatário? Qual é a força da influência deste sobre o enunciado?"( BAKHTIN, 2000, p. 321). 
O teórico ainda argumenta que quando o sujeito fala e/ou escreve sempre considera o seu destinatário e leva em conta o grau de informação que ele tem da situação comunicativa, seus conhecimentos, suas opiniões e suas convicções. Esses aspectos são os determinantes na "escolha do gênero do enunciado, a escolha dos procedimentos composicionais e, por fim, a escolha dos recursos linguísticos, ou seja, o estilo do meu enunciado" (BAKHTIN, 2000, p. 321).

Dessa forma, ao iniciar um trabalho com os gêneros aqui selecionados, o professor deve partir, como mencionado, dos aspectos socio-históricos dos gêneros e lançar os primeiros questionamentos de análise: De quem? Para quem? Onde? Indissociável dessa primeira etapa, o professor passa para a descrição do gênero e, posteriormente, para a interpretação. Quando nos referimos à etapa de descrição do gênero, entendemos que nela são abordadas questões acerca das dimensões do gênero (tema, estilo e composição), juntamente com os elementos que levem a contemplar a esfera comunicativa que circula os gêneros, a questão do cronotopo (tempo e lugar histórico), relações sociais, apreciação valorativa, modalidade de linguagem (ROJO, 2005). A última etapa está relacionada com a análise/forma linguística.

O gênero 1 se refere a uma conversa oral. A conversa foi gravada em uma loja na esfera comercial de Jaguarão, cidade que faz fronteira com a cidade uruguaia de Rio Branco.

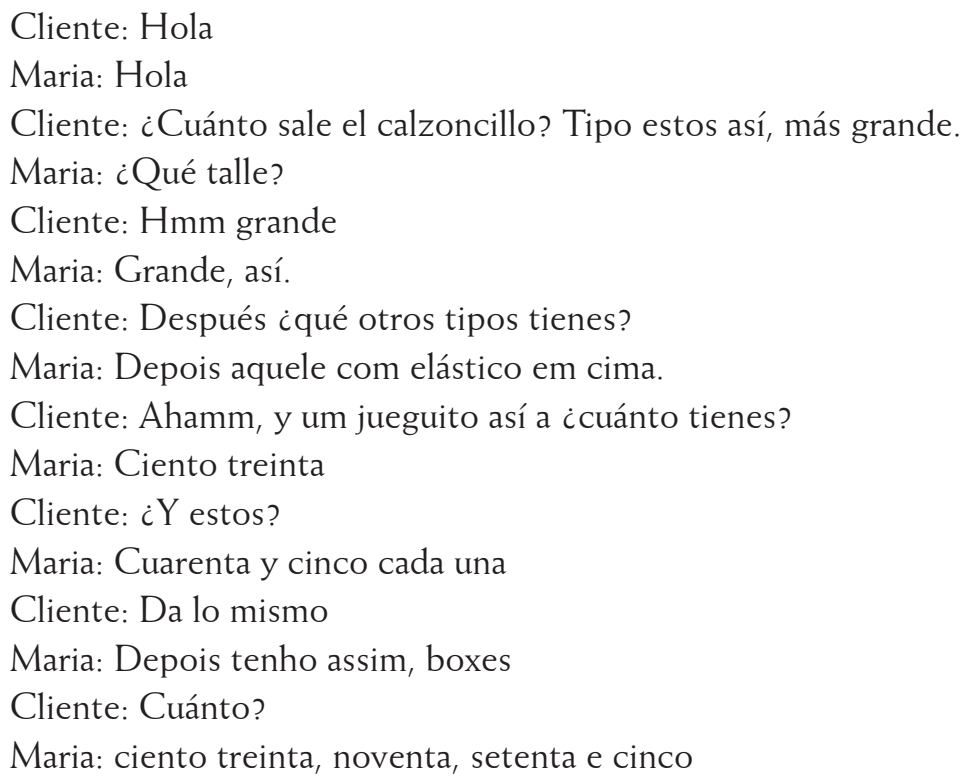

Cliente: Hola

Maria: Hola

Cliente: ¿Cuánto sale el calzoncillo? Tipo estos así, más grande.

Maria: ¿Qué talle?

Cliente: Hmm grande

Maria: Grande, así.

Cliente: Después ¿qué otros tipos tienes?

Maria: Depois aquele com elástico em cima.

Cliente: Ahamm, y um jueguito así a ćcuánto tienes?

Maria: Ciento treinta

Cliente: ¿Y estos?

Maria: Cuarenta y cinco cada una

Cliente: Da lo mismo

Maria: Depois tenho assim, boxes

Cliente: Cuánto?

Maria: ciento treinta, noventa, setenta e cinco 


\section{Cliente: Y las medias finas \\ Maria: Cuarenta y cinco \\ Cliente: Gracias \\ Maria: sempre às ordens}

Os interlocutores são a vendedora brasileira e a cliente uruguaia o que justifica a escolha da língua espanhola no discurso daquela para efetivar a venda. Este gênero nos mostra o que Gonçalves (2013) defende na sua dissertação: essa amostra ilustra a alternância de línguas existente na fronteira bilíngue Jaguarão/Rio Branco com uma conversa entre uma vendedora e uma cliente uruguaia no comércio local. Na amostra, podemos observar que o encontro das duas línguas no mesmo gênero ocasiona o que neste trabalho estamos chamando de "mistura" de línguas. Essa "mistura", no nosso entendimento, não é entendida como o conhecimento deficiente de uma ou outra língua por parte dos sujeitos e tampouco como uma incapacidade linguística dos falantes, mas sim a entendemos como "um recurso adicional dos bilíngues, para que possam expressar-se nas mais diversas situações" (GONÇALVES, 2013, p. 36).

A "mistura" que aparece neste gênero está relacionada com o que apontamos na seção 2: a alternância de línguas perpassa toda a conversa. Maria, a vendedora, inicia utilizando a língua espanhola "Maria: Hola" e assim prossegue "Maria: ¿Qué talle?; Maria: Ciento treinta Maria: Cuarenta y cinco cada una" até alternar para o português "Maria: Depois aquele com elástico em cima. Maria: Depois tenho assim, boxes e, assim se despede "Maria: sempre às ordens".

O gênero 2, diferente do primeiro, se caracteriza por ser um gênero literário secundário. É um poema de autoria do escritor e professor uruguaio fronteiriço Fabián Severo.

Yo no quiria ir mas en la escuela

purque la maestra Rita, de primer año

cada ves que yo ablava

pidía pra que yo repitiera y disía

vieron el cantito na vos del, asín no se debe ablar

y todos se rían de mim

como eya pidía que yo repitiera

yo repitía y eyos volvían se ri

otras ves disía ella,

en su casa no le lavan la túnica 
no dicen que tiene que cuidarla y tenerla linpita.

Yo no me animava desir que ella

Que la túnica era del Caio

i ele me imprestava purque sinó yo no tiña pra ir.

Yo no pudía ir en los paseo porque nunca tiña ropa.

Una vuelta nos iva ir a Beya Unión

Pra un campeonato de fútbol

Yo jugaba mui bien i mis amigo quirían que fuera

Mas como no tiña champión

Me vendé el braso i dice que me avía lastimado

I que pur iso no pudía viayar.

Yo no quiría ir mas na escuela

Porque tudo el mundo sabía

Que los que ivan nel comedor eran pobre.

Tocava la compana i todos se ivan

Nos se mitía na fila

I todos nos mirava.

Yo tiña vergonha.

Asvés creo que eu so así

Meio tímido

Porque yo sempre era el pobre.

Mi madre dis que vergoña es robar

I que cuando eya iva na escuela

Sempre tentava se meter dos ves na fila

Pra poder agarrar mas pan i yevar pras casa

I me dis

Acá me ves sana i gorda, asín que no sinta vergüensa mijo.

Os poemas do livro Noite nu norte estão inseridos em um espaço onde se pode falar português e espanhol "entreverado" porque acontece no contexto fronteiriço, considerando as condições socio-históricas desse lugar. Dirige-se tanto ao sujeito na fronteira, que é um sujeito que circula em um espaço de enunciação peculiar, como aos apreciadores de uma boa literatura fortemente marcada pelas condições sociolinguísticas da fronteira. Severo nos mostra, como diz Behares (2010), uma variedade do português falado em Artigas: um portunhol com características linguísticas específicas. ${ }^{3}$ 
Nesse poema, para a maestra não era possível falar com el cantito na escola, isso era sinônimo de não saber falar, de não dever-se falar assim, ali era lugar de um outro falar, a escola era, e ainda é, o lugar do espanhol, da imposição da língua espanhola e da demarcação da linha de fronteira. No lugar de contenção chamado escola, é-se sujeito uruguaio, não se pode ser fronteiriço. A escola é uma extensão reguladora do Estado-Nação uruguaio, reforçando a ideia de que nesse espaço específico não se aceitarão outras práticas linguísticas, a não ser uma variedade de prestígio da língua espanhola, solidificando o espanhol padrão e eliminando as falas consideradas incorretas que há no lugar.

O gênero 3 é um gênero que circula na zona comercial de Rio Branco, ligado a esse espaço, a essa esfera de atividade humana que possui a sua própria forma de produção, de circulação e de recepção de discursos. Quem escreveu o anúncio trabalha no restaurante divulgado, que tem como destinatário principal o turista brasileiro.

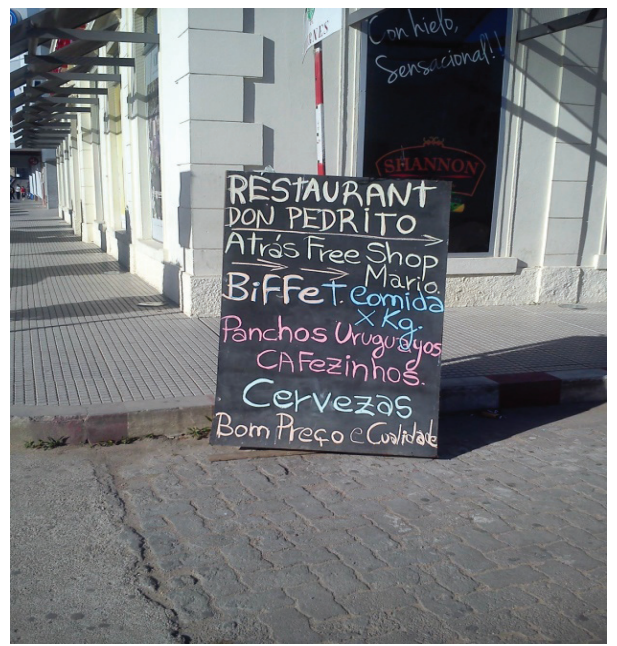

Figura 1

Nesse gênero, podemos observar como a diferença cultural está bem marcada. Primeiro, com a referência que se faz sobre a oferta de "biffet" "x kg" (lê-se por

3 Gostaríamos de explicitar que não há nenhuma intenção de falar dos poemas de Fabián Severo tratando-os a partir de uma perspectiva de análise literária e considerando-os como representativas do eu/yo lírico que materializa a sua particularidade linguística com características de prática linguística fronteiriça. Não há a intenção de estabelecer uma comparação entre o Norte e o Sul do Uruguai com relação às diferenças linguísticas entre essas regiões. Há sim o objetivo de evidenciar algumas práticas linguísticas que ocorrem na cidade de Jaguarão e outras práticas que são representativas no livro de Severo, que ficticiamente são ambientadas na cidade de Artigas. 
kilo). Entendemos que a expressão "comida por kg" quer demarcar, de certo modo, a questão da diferença. No Uruguay, comparado ao Brasil, por exemplo, a maioria dos restaurantes uruguaios não oferecem comida por $\mathrm{kg}$ e sim a la carte. Percebe-se que é uma diferença cultural bem marcante e nesse anuncio há essa desmobilização. Ademais, talvez o acréscimo da palavra "comida" foi usado para que não houvesse dúvida de que o "biffet" é de comida e não de doces, sorvetes, serviço encontrado no Brasil e não no Uruguai, por exemplo.

Outra diferença demarcada em relação à comida está representada pela venda de "panchos uruguayos" que também é mencionada no anúncio. O pancho uruguayo também é outra comida típica do Uruguai, uma iguaria que não encontramos no Brasil. Observamos, novamente, a apelação do anúncio a essa diferença cultural que atrai os turistas brasileiros

O anúncio finaliza com a expressão "bom preço e cualidade". Nessa expressão, observamos que, na tentativa de escrever em língua portuguesa, o sujeito utiliza a expressão "bom preço", porém a palavra que seria "qualidade" inicia escrevendo em língua espanhola e termina com o acréscimo da vogal " $\mathrm{e}$ ": "cualidade", indicando a tentativa de escrever em língua portuguesa para aproximar-se do seu interlocutor.

Essas estratégias causam efeitos discursivos específicos, justamente porque acompanham a evolução das interações verbais e são tipicamente usadas pelos sujeitos fronteiriços em práticas discursivas situadas. A representação sobre a linguagem, nesse contexto, que leva o sujeito fronteiriço a valer-se dos usos transidiomáticos presentes nesses anúncios está relacionada com a arte de interagir com o turista apresentando um estabelecimento comercial e o que o sujeito leitor vai encontrar nesse lugar aspectos diferentes da cultura uruguaia que são fortes atrativos para o turista brasileiro.

$\mathrm{O}$ uso translíngue visto como recurso comunicativo/estratégia comunicativa nos mostra que os interlocutores transitam pelas duas línguas (português brasileiro e espanhol uruguaio), e, por isso usam em seus textos transidiomáticos "pedaços" ora de uma ora de outra. Cabe saber como o turista brasileiro que lê esse anúncio o interpreta: se é pelo viés da integração e se sente envolvido pelo contexto e assim considera o interlocutor, a função discursiva e a quem o anúncio foi dirigido, ou pelo viés do desprestígio linguístico em que só se vê a forma pela forma ao elencar no seu ponto de vista "erros" e não a prática comunicativa como um todo.

Entendemos que os usos transidiomáticos presentes nos anúncios, além de destacarem o interlocutor típico (o turista), apontam para um hibridismo orgânico, pois o uso das duas línguas no mesmo projeto enunciativo não foi previamente 
planejado, mas sim mostra o que o ambiente proporciona e os sentidos que os sujeitos mobilizam a partir do repertório linguístico que possuem.

O gênero 4, que também circula na fronteira Jaguarão-Rio Branco, infere-se que é produzido por profissionais que buscam divulgar uma festa noturna de final de ano. Os interlocutores envolvidos são brasileiros e uruguaios. Cabe ressaltar que alguns organizadores do evento são uruguaios e outros são brasileiros e buscam nessa festividade integrar os países, línguas e sujeitos. Nele também se percebe o uso ora da língua espanhola "atracciones", "diversión", "integración", ora da língua portuguesa "lançamento de camisetas", "trio trem bala", "banda Tamiflu".

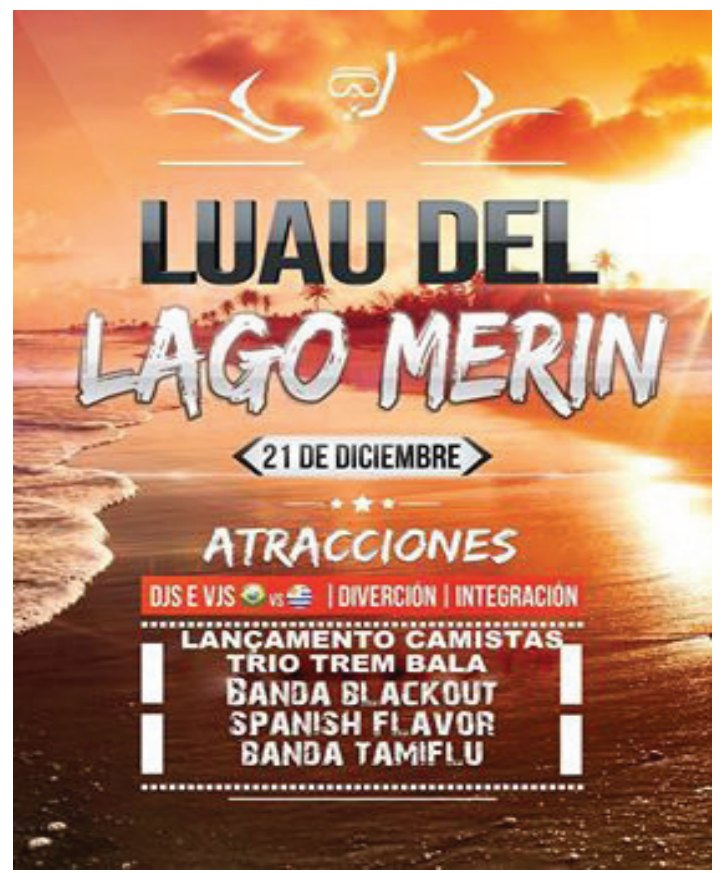

Figura 2

Igualmente ao gênero anterior, o gênero 5 divulga uma festa de Natal que ocorreu na cidade de Rio Branco. Os organizadores são brasileiros e uruguaios e os interlocutores também são binacionais. Tal gênero circula em ambas as sociedades e principalmente na esfera de promoção de eventos. A partir desses dados, entendese que os produtores do gênero são de ambas as nacionalidades, assim como os interlocutores e, como sujeitos de fronteira, buscam ao promoverem as suas festas manifestar na materialidade linguística a integração que acontece no cotidiano, inserindo na escrita o que já é realidade na fala dos sujeitos que transitam entre as 
duas cidades. Nesse contexto, valem-se das duas línguas para a produção do gênero que segue.

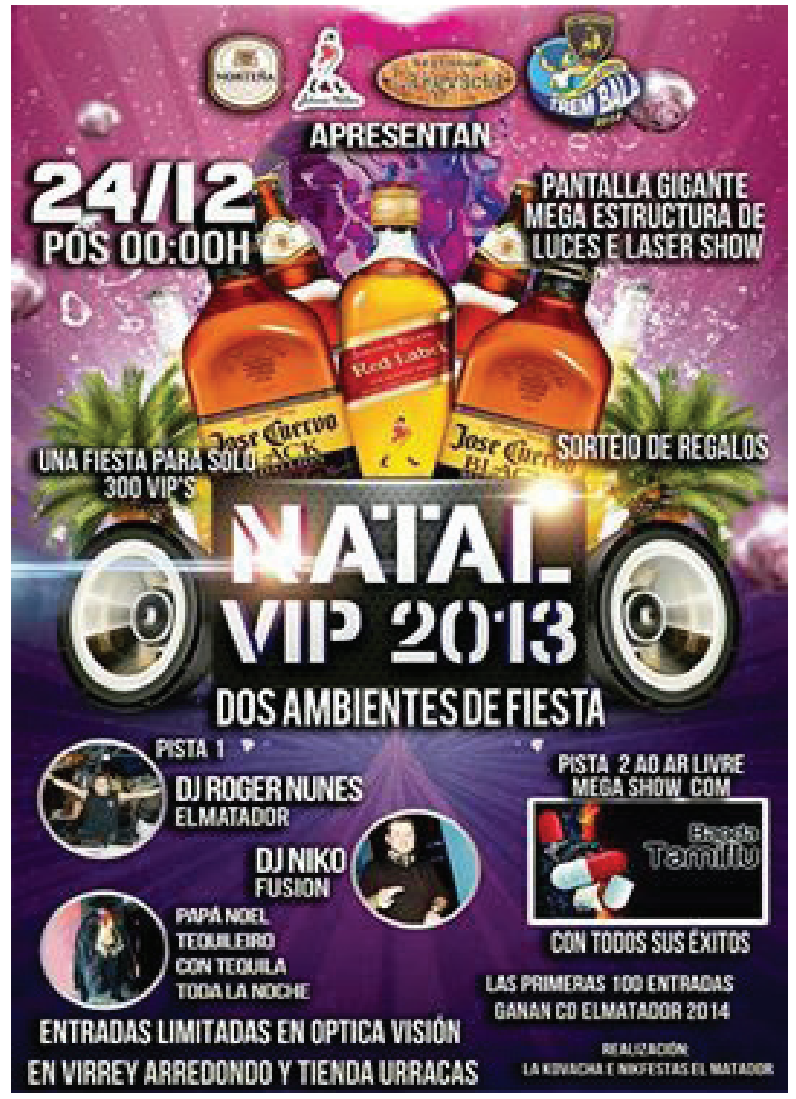

Figura 3

Percebemos que perpassa o folheto uma combinação das línguas: ora a língua portuguesa, ora a língua espanhola. Essa combinação ocorre, por exemplo, no enunciado "sorteio de regalos"; "Natal Vip 2013 dos ambientes de fiesta".

Essas combinações podem ser consideradas recursos comunicativos que se definem como o uso de "pedaços pequenos e grandes da língua que constituem um repertório, e os modos verdadeiros de usar tal repertório na comunicação" (BLOMMAERT 2010 apud Moita Lopes, 2013, p.113), tais recursos têm efeitos de sentidos situados em espaços onde o fluxo de sujeitos reflete uma dinâmica linguística e sociolinguística peculiar nesse contexto de fronteira.

Os usos translinguísticos, ou seja, o uso do espanhol e do português combinados é um recurso comunicativo, uma estratégia comunicativa usada 
por sujeitos participantes das práticas discursivas fronteiriças, e estão calcadas na expressiva negociação discursiva e não na busca de constructos unitários de língua (CANAGARAJAH, 2007 apud MOITA LOPES, 2013).

Diante disso, buscamos iniciar uma reflexão sobre o tratamento de gêneros que circulam na fronteira e lançar um olhar para os modos como os sujeitos, nos espaços fronteiriços, "vivem/constroem suas vidas sociais por meio da linguagem nas práticas linguísticas em que estão situadas" (MOITA LOPES, 2013, p, 106). Sobral (2009) afirma que "ensinar gênero é mostrar o que são e como funcionam os gêneros, quais os projetos enunciativos a que servem, recorrendo a vários tipos de textualidades". Isso justifica o olhar analítico traçado por nós, que não é único, para a discussão dos referidos gêneros em sala de aula.

Nessas práticas, os sujeitos usam as línguas e seus repertórios linguísticos para se comunicar em uma sociedade em que línguas, sujeitos, textos, discursos estão em mobilidade constante, portanto longe da unificação, da homogeneidade e mais próximos das recombinações comunicativas.

Somado a isso, Bakhtin/Voloshinov (1929, p. 95) argumentam que um ensino prático parte de um método o qual "exige que a forma seja assimilada não no sistema abstrato da língua, isto é, como uma forma sempre idêntica a si mesma, mas na estrutura concreta da enunciação, como um signo flexível e variável".

Bakhtin (1992, p. 156) afirma que, "a linguagem participa na vida através dos enunciados concretos que a realizam, assim como a vida participa da vida através dos enunciados". Nesse contexto, as esferas de uso da linguagem são "referência direta aos enunciados concretos que se manifestam nos discursos" (BAKHTIN, 1992, p. 156) e os gêneros analisados adquirem matizes do contexto fronteiriço, pois é somente nas relações dialógicas e situadas que surgem os sentidos esperados. Como Bakhtin/Voloshinov (1929, p 112) sustentam que "qualquer que seja o aspecto da expressão-enunciação considerado, ele será determinado pelas condições reais da enunciação em questão, isto é antes de tudo pela situação social mais imediata".

$\mathrm{O}$ que se mostra com esses gêneros é mais um exemplo típico dos usos linguísticos que circulam na fronteira e o modo como os sujeitos fronteiriços constroem em situações (tempo, espaço e sujeitos envolvidos) e esferas específicas os sentidos cujo entendimento requer pensar língua/linguagem de um modo que se distancia de um conceito homogêneo e unitário. 


\section{CONSIDERAÇÕES FINAIS}

Concordamos com Sobral (2009, p. 99) quando este afirma que somente entendemos o evento verbal se conhecemos as "circunstâncias pragmáticas de produção desse enunciado". Os enunciados analisados são marcados por uma enunciação que remete a uma esfera específica da atividade humana e a um contexto comunicativo específico: a(s) fronteira(s) geográficas e linguísticas.

Ao discutir as designações até o momento utilizadas na bibliografia dos estudos de fronteira, não tivemos a intenção de fazer juízo de valor sobre uma ou outra designação. Objetivamos com isso apenas tensionar e compreender as imbricações linguísticas e pedagógicas que perpassam em algumas delas a partir de amostras de gêneros que circulam nas fronteiras entre Brasil e Uruguai.

Diante da singularidade linguística que caracteriza a região de fronteira em que a Unipampa está inserida, entendemos que tal característica linguística deve ser cuidadosamente considerada nos Cursos de Letras bem como as implicações pedagógicas que decorrem de tal inserção.

Essa atenção e cuidado se justificam porque não há nas fronteiras apontadas, uma identificação única - como mostra muito bem o estudioso Rona (1965), mas sim uma identificação líquida que vai buscando acomodar-se aos contextos de interação. E nesse fluxo em intenso movimento e sem um enquadramento único e fixo novas designações aparecem, proporcionando que novos objetos de estudo sejam discutidos pelos investigadores que se interessam pelo encontro de línguas, sujeitos, identidades e fronteiras geográficas e discursivas.

Por fim, entendemos que falar em e sobre um espaço sociodialógico fronteiriço é buscar um movimento que valorize o conflito linguístico, conflito esse situado longe do desprestígio, porque é característico desse espaço fronteiriço. Diante disso, defendemos que se considere a mistura, o entrelaçar de línguas, a mistura de famílias, a mistura de culturas, a mistura de identidades como uma interrogante para os estudiosos da linguagem e professores que vivem e trabalham nas fronteiras. Entendemos que a partir do momento em que se valoriza a variedade de língua da fronteira também há a valorização do aluno que fala "mistura", que usa o "portunhol" para comunicar-se e que traz a fala fronteiriça para o lugar do embate, que é a escola ou a instituição de ensino superior na qual vai estudar. Para encerrar, concordamos com as palavras de um reconhecido escritor jaguarense o qual enuncia que transitar nesse espaço "é ir ao exterior sem sair do interior, é ir ao estrangeiro sem ser forasteiro, é sentir-se cosmopolita dentro de casa (...), é 
descobrir o resto do mundo no próprio espelho, ante a conformidade das margens opostas" (SCHLEE, 2010, p. 260).

O professor em formação deve colocar-se na posição de interlocutor desse espaço para que, além de analisar o contexto de produção, possa identificar efeitos de sentido e minimizar os conflitos que os enunciados ali proferidos criam em uma zona/região/cidade de fronteira e, mais ainda, quando circulam no ambiente de ensino/aprendizagem institucional que tradicionalmente regula as línguas.

\section{REFERÊNCIAS BIBLIOGRÁFICAS}

BAKHTIN, M. (VOLOSHINOV). Marxismo e filosofia da linguagem. Problemas fundamentais do método sociológico na ciência da linguagem. Trad. Michel Lahud e Yara Frateschi Vieira. São Paulo: Hucitec, 1986.

BAKHTIN, M. Estética da criação verbal. 5ed. Trad. Paulo Bezerra. São Paulo: Martins Fontes, 1992.

BEHARES, L. (orgs.) Fronteiras, educação, integração. Santa Maria: Pallotti, 1996.

CATAIA, M. A. Transcrição da mesa-redonda "Fronteiras: Territórios em Conflitos" do XIII Encontro Paranaense de Estudantes de Geografia (EPEG), apresentada na noite de 23 de maio de 2008, na Universidade Estadual do Oeste do Paraná (UNIOESTE), campus de Marechal Cândido Rondon.

CORREA, J.; DORNELLES, C. Práticas de letramento em séries iniciais: Um estudo em uma escola da fronteira Brasil/Uruguai. Anais do II Congresso Linguagem e Interação. São Leopoldo: UNISINOS, Jun. 2010

ELIZAINCIN, A.; BEHARES, L. ;BARRIOS,G. Nos falemo Brasileiro: Dialectos portugueses en Uruguay. Montevideo: Amesur, 1987.

FERNANDES, I. C. S.; STURZA, E. R. A fronteira como novo lugar de representação do espanhol no Brasil. Signo \& Seña. El español en Brasil. Investigación, enseñanza, políticas. n. 20. Universidad de Buenos Aires/Instituto de Linguística, jan./2009. p. 207-228.

FUSTES,J. M. Lengua y sujeto en las investigaciones acerca de la frontera uruguaya con Brasil: apuntes sobre sus determinaciones teóricas. In: GONÇALVES, Dania Pinto. O falar dos comerciantes brasileiros na fronteira de Jaguarão-Río Branco. 2013. 137 f. Dissertação (Mestrado) - Programa de Pós-Graduação em Letras. Universidade Federal de Pelotas, Pelotas.

GONZÁLEZ, N. M.. Desejos, crenças e projetos que marcam o percurso do ensino de E/ LE no Brasil. In: FANJUL, A. P.; CASTELA, G. S. (Org.). Línguas, políticas e ensino na integração regional. Cascavel: ASSOESTE, 2011.

IRALA, V.; MOTA, S. S. ALVAREZ, I. M. J. Brasil. Formar professores de espanbol no Brasil em regiões de fronteira: múltiplos desafios in Revista Eletrônica do GEPPLE, Grupo de Estudos e Pesquisa sobre Práticas de Ensino e Formação de Professores de Espanhol 
Departamento de Letras Estrangeiras - Universidade Federal do Ceará Ano I Edição No 02 - v. 1 - Nov./2013 Maio/2014, p. 64-86, 2013.

MOTA, S. dos S. Línguas, sujeitos e sentidos: o jornal nas relações fronteiriças no final do século XIX, início do século XX. Universidade Federal de Santa Maria. (Dissertação de mestrado), 2010.

PADRÓS, E. Fronteiras e integração fronteiriça: elementos para uma abordagem conceitual. Humanas, Porto Alegre, v.17, n.1/2, p.63-85, jan/dez.,1994.

PESAVENTO, S. Além das fronteiras. In: MARTINS, Maria Helena(org). Fronteiras culturais: Brasil-Uruguai-Argentina. São Paulo: Ateliê Editorial, 2002.

MACHADO, L. O. Limites, fronteiras, redes. In STROHAECKER, T. M. et. al. (org). Fronteiras e Espaço Global. Porto Alegre: AGB-Porto Alegre, 1998, p 41 -49.

MOITA LOPES, L. P da (org). Português no século XXI: cenário geopolítico e sociolinguístico. São Paulo: Parábola Editora, 2013.

RONA, J.P. La frontera lingüística entre el portugués y el español en el norte del Uruguay. VeritasPontifícia Universidade Católica do Rio Grande do Sul, Porto Alegre, 1963.

RONA, J. P. El dialecto "fronterizo" del norte del Uruguay. Montevideo. Adolfo Linardi, 1965.

SCHLEE, A. G. Testemunhos de identidades. In: SCHULER, F. L.; BORDINI, M.G. (org). Culturas e Identidade Regional. Porto Alegre: EDIPUCRS, 2014.

SEVERO, F. Noite nu norte. Montevideo: Ediciones del Rincón, 2010.

SOARES, E. A. S; FRANCO, S. C. (orgs). Olhares sobre Jaguarão. Porto Alegre: Evangraf, 2010.

SOBRAL, A. Do dialogismo ao gênero: as bases do pensamento do Círculo de Bakbtin. Campinas: Mercado das Letras, 2009.

STURZA, E. Línguas de fronteira: o desconbecido território das práticas linguísticas nas fronteiras brasileiras. Revista Ciência e Cultura. SBPC. ano 57, n. 2, abr./maio/jun. 2005. Temas e Tendências: Línguas do Brasil.

Revista Eletrônica do GEPPELE - Grupo de Estudos e Pesquisa sobre Práticas de Ensino

e Formação de Professores de Espanhol Departamento de Letras Estrangeiras - Universidade Federal do Ceará Ano I - Edição No 02 - Vol. I - Nov./ 2013 Maio/2014.

Recebido: 12/03/2015

Aceito: 05/10/2015 